\title{
Unsteady Couette Flow of Dusty Fluid Past Between Two Riga Plates
}

\author{
Mohammad Rafiqul Islam ${ }^{1}$ and Sonia Nasrin ${ }^{2}$ \\ ${ }^{1}$ Bangabandhu Sheikh Mujibur Rahman Science and Technology University \\ ${ }^{2}$ Jagannath University
}

July 18, 2020

\begin{abstract}
The present study is carried out on the unsteady laminar heat transferable dusty fluid flow past between two parallel Riga plates. The lower plate is kept fixed while the upper plate keeps moving with a constant velocity. A uniform Lorentz forces induced by Riga plates and a constant pressure gradient is applied on the fluid. The governing equations are derived from Navier-Stokes equation, Energy equation. Boundary layer approximations have been employed. The motion of the dust particles is governed by Newton's second law. The non-dimensional equations are solved by using the explicit finite difference method. The effects of necessary parameters on the velocity and temperature distributions as well as the shear stress and Nusselt number of clean fluid particle and dust particles have been discussed in detail.
\end{abstract}

\section{Hosted file}

Manuscript.pdf available at https://authorea.com/users/343928/articles/470548-unsteadycouette-flow-of-dusty-fluid-past-between-two-riga-plates 